\title{
Legg-Calvet-Perthes disease and aseptic necrosis of the femoral head: MRI-semiotics of the terminal disease stage with outcome in deforming arthrosis
}

\author{
G.V. Diachkova, M.P. Teplenky, K.A. Diachkov, T.A. Larionova
}

Ilizarov National Medical Research Centre for Traumatology and Orthopedics, Kurgan, Russian Federation

\begin{abstract}
Introduction The changes that occur in the femoral head in Legg-Calvet-Perthes disease and aseptic necrosis in the early stages have been described sufficiently. The aim of the work was to study the condition of the hip joint in patients with LeggCalve-Perthes disease and aseptic necrosis of the femoral head with magnetic resonance imaging (MRI) in the terminal stages of the disease and by formation of a symptomatic complex of deforming arthrosis. Materials and methods A retrospective single-centre MRI study (case series) included 15 patients with aseptic necrosis of the femoral head and Legg-Calve-Perthes disease. Results Among the studied group of patients, patients with stages III-IV of the disease prevailed. Five patients in the third - fourth stage of the disease had complete horizontalization of the cartilaginous labrum as a result of the outward displacement of the head. In seven patients, horizontalization was less pronounced, and the angle of the cartilaginous labrum ranged from 5 to $10^{\circ}$. The study of the cartilaginous acetabular index showed that in 9 out of 13 patients its value was less than 75-77 \%. In stages III-IV, changes in the shape of the head and its lateralization is more pronounced. Discussion The complex of pathological changes in the hip joint in Legg-Calvet-Perthes disease and aseptic necrosis of the femoral head, especially in children, is most fully revealed with MRI, allowing to assess the state of the femoral head, acetabulum, all soft tissue and cartilaginous formations of the joint. One of the most important indicators is the lateralization of the cartilaginous labrum which reflects the severity of the mechanical stress in it resulting in displacement of the femoral head.

Keywords: hip joint, aseptic necrosis of the femoral head, Legg-Calve-Perthes disease, MRI
\end{abstract}

\section{INTRODUCTION}

According to the literature, the incidence of LeggCalve-Perthes disease varies not only in different countries, but also within relatively small areas of one city. It ranges from 0.4 / 100,000 to 29.0 / 100,000 cases [1-5]. Most studies link the disease process with combined effects of genetic predisposition, increased leptin levels, altered differentiation of mesenchymal stem cells, mutation of factor $\mathrm{V}$ of the hemostatic system, and other changes [1, 6-8]. Changes that occur in the femoral head in Legg-Calvet-Perthes disease in the early stages have been studied using a complex of modern diagnostic methods (MSCT, MRI, ultrasonography) [9-11].

Various classifications are used to determine the stage of the Legg-Calve-Perthes disease [10, 12-14]. MRI is the most effective means for detecting the early stage of the disease $[10,15,16]$.

A large number of studies have been devoted to aseptic necrosis (AN) of the femoral head [17, 18, 19]. The key moment of the pathological chain of events in the development of non-traumatic aseptic necrosis is the disturbance of blood circulation in the microvasculature, provoking ischemia and bone tissue destruction $[8,10,20,21]$. One of the main problems discussed by radiologists and orthopaedists is the classification of the severity of the damage to the femoral head in aseptic necrosis in order to address the need, timing and method of treatment $[9$, 22, 23]. There are at least 16 different classifications $[12,24,25,26]$. The emergence of magnetic resonance imaging (MRI) as the method of choice in the study of AN and its widespread use led to the emergence of the osteonecrosis classification system, Steinberg University of Pennsylvania osteonecrosis classification system, Association Research Circulation Osseous based on MRI data. Stages 1 through 4 are classified by the percentage of femoral head involvement: $\mathrm{A}<15$, B $15-30 \%, \mathrm{C}>30 \%$ [26]. However, it is not only the severity of the damage to the head that matters but also other components of the hip joint (acetabulum, capsule, muscles), which determine the choice of treatment method and dictates the use of MRI as the most effective method of not only early, but also detailed visualization of pathological changes in the hip joint.

Purpose To study the condition of the hip joint in patients with Legg-Calve-Perthes disease and with AN of the femoral head with MRI in the terminal stages of the disease and during the formation of a symptomatic complex of deforming arthrosis.

[D Diachkova G.V., Teplenky M.P., Diachkov K.A., Larionova T.A. Legg-Calvet-Perthes disease and aseptic necrosis of the femoral head: MRI-semiotics of the terminal disease stage with outcome in deforming arthrosis. Genij Ortopedii, 2020, vol. 26, no 3, pp. 370-375. DOI 10.18019/1028-4427-2020-26-3-370-375 


\section{MATERIAL AND METHODS}

A retrospective single-center study (case series from January 2018 to January 2020) included 15 patients with AN of the femoral head and Legg-Calve-Perthes disease aged 5 to 18 years (level of evidence: case series (V); study case series with a definite diagnosis does not suggest a control group) [27].

Two patients had bilateral disorders. The patients were examined with MRI. The study was performed on a Magnetom Symphony magnetic resonance image system (1.5 T), Siemens. The $\mathrm{t} 2$ tse and $\mathrm{t} 1 \mathrm{fl} 2 \mathrm{~d}$ modes were used, with and without fat signal suppression. In the frontal, axial and sagittal sections, the thickness of the articular cartilage and the height of the growth zone were measured. The structure of the femoral head and the acetabulum was studied. The MR signal was assessed in comparison with the contralateral side. In addition, the angle of the acetabular labrum was defined. It depended on the change in the head contours and its lateralization, decreased to zero if the labrum was completely horizontal, or had a negative value (Fig. 1).

The study was carried out in accordance with the Declaration of Helsinki of the World Medical
Association "Ethical principles for conducting scientific medical research with human participation" as amended in 2000 and the "Rules of Clinical Practice in the Russian Federation" approved by the Order of the Ministry of Health of the Russian Federation dated June 19, 2003 No. 266. All the persons participating in the research or their legal representatives signed an informed consent for participation and publication of data without personal identification. Inclusion criteria were children with Legg-Calve-Perthes disease and aseptic necrosis of the femoral head at the age between 5 and 18 years. Individuals over 18 years of age were excluded.

The data were statistically processed using the Microsoft EXCEL 2010 data analysis package and the Attestat 2001 software. To determine the normality of the distribution of the sample, the Shapiro - Wilk test was used. With a normal distribution of quantitative indicators, Student's t-test was used. In other cases, nonparametric methods were used (Mann - Whitney test, Wilcoxon test). The accepted level of significance was $\mathrm{p}<0.05$.
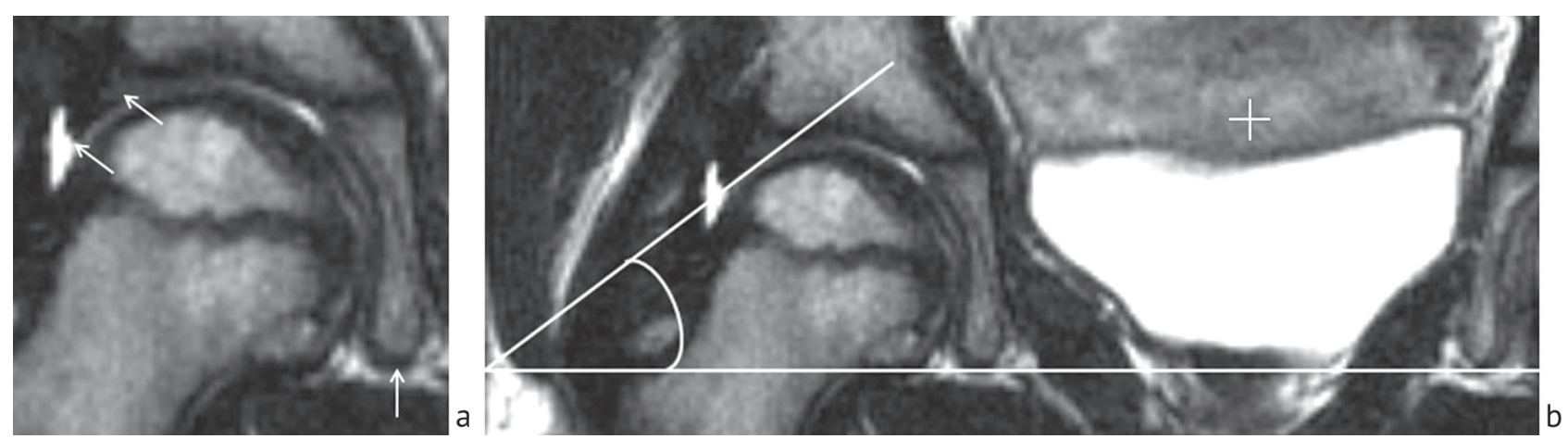

Fig. 1 MRI of the hip joints, coronal T2WI; measurement of the angle of the labrum (AL). The angle is formed by the intersection of the line connecting the most distal point (white arrow, a) of both teardrop figures, and the line connecting the most proximal and distal points (two arrows, $a$ ), where the upper labrum contacts the proximal femoral epiphysis $(b)[10]$

RESULTS

The nature of changes in the femoral head in patients with Legg-Calve-Perthes disease depends on the stage of the process and the individual characteristics of the course of the disease. However, many patients refer to doctors when changes in the femoral head go far beyond stages 1-2, and radiographic morphological and MRI changes in the head (stages 3-4) cannot be assessed using the proposed quantitative schemes. The first stage of the disease, which is most clearly visualized in MRI, was not detected in any of the patients we examined. Two patients had the second stage of the disease, which was characterized by the demarcation of the area of necrosis (Table 1).

Table 1

Distribution of patients with Legg-Calve-Perthes desease according to age and disease stage

\begin{tabular}{|c|c|c|c|}
\hline \multirow{2}{*}{ Stage } & \multicolumn{3}{|c|}{ Age (years) } \\
\cline { 2 - 4 } & $5-8$ & $9-12$ & $13-18$ \\
\hline 2 & 2 & - & - \\
\hline 3 & 1 & 3 & - \\
\hline $3-4$ & - & 2 & 8 \\
\hline
\end{tabular}

The intensity of the necrotic area image in different sequences may differ depending on the nature of the changes identified in the destruction zone. Therefore, four types of MR images are distinguished. In the presented case, the necrotic focus had a hypointensive signal on T1WI and T2WI (Fig. 2). 


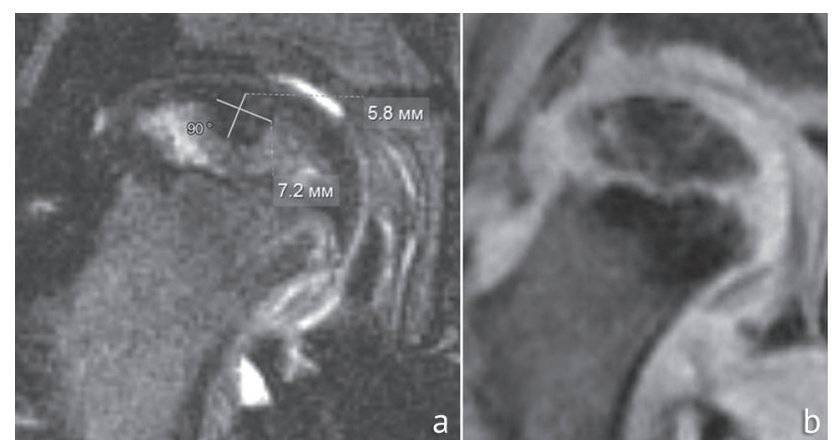

Fig. 2 MR-tomogram of the hip joints of patient I., 8 years old. Legg-Calvet-Perthes disease, stage 2; $\mathrm{t} 2$ tse cor fs $(a)$; $\mathrm{t} 1-\mathrm{fl} 2 \mathrm{~d}$ fs, coronal plane $(b)$

The femoral head was moderately flattened and widened; its diameter was $3.9 \mathrm{~cm}$ (the opposite side $-3.5 \mathrm{~cm}$ ). The ossification nucleus was of a heterogeneous structure, fragmented in the anteromedial part measuring $2.6 \times 2.6 \times 1.08 \mathrm{~cm}$. The articular cartilage was locally thickened to $3.9 \mathrm{~mm}$ (opposite side $-2.3-2.9 \mathrm{~mm}$ ). The epiphyseal growth zone had an uneven height, from 1.2 to $2.0 \mathrm{~mm}$. The height of the growth zone of the healthy limb was $2.8 \mathrm{~mm}$ along the entire length. There was a moderate effusion in the articular cavity on the side of necrosis.

In both second-stage cases, secondary exudative synovitis was detected, as well as manifestations of a chronic inflammatory process manifested by hypertrophy of the synovial membrane, varying severity of changes in the capsule and cartilage. The thickness of the articular cartilage of the acetabulum differed. Foci of varying intensity were determined in the body of the ilium on T1WI.

Four patients had stage 3 of the disease (stage of impression fracture). In MRI tomograms, flattening and fragmentation of the epiphysis were determined. The hyaline cartilage, covering the femoral head and acetabulum, was of uneven thickness and of heterogeneous structure. The amount of effusion in the articular cavity was increased. In five patients, changes in the roof of the acetabulum were expressed: an uneven deformed contour, an inhomogeneous signal, especially along the edge of the cavity, fragmentation of the cartilage. In two patients, marginal defects were observed against the background of an uneven acetabular roof contour. In five patients in the third/fourth stages of the disease, complete horizontalization of the acetabular labrum occurred due to outward displacement of the head, while the cartilaginous labrum was at the same level with the roof of the acetabulum (Fig. 3).

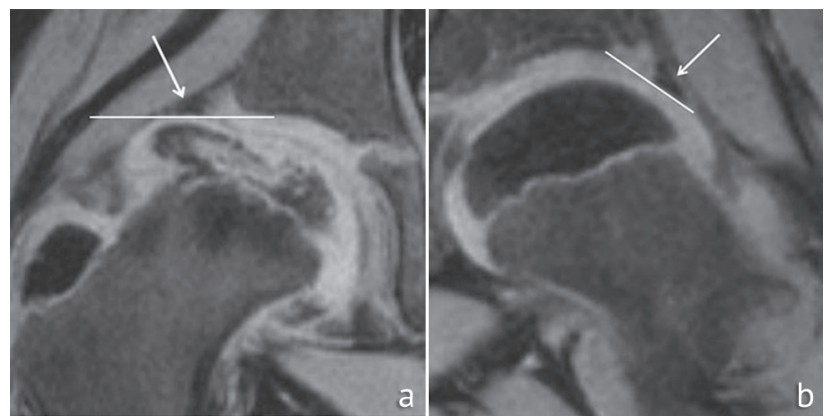

Fig. 3 MR-tomogram of the hip joints of patient P., 10 years old. Legg-Calvet-Perthes disease in stage 3; t1 fl2d fs, coronal plane. Horizontalization of the acetabular labrum $(a)$ versus the healthy side $(b)$

In seven patients, horizontalization was less pronounced, and the angle of the acetabular labrum ranged from 5 to $10^{\circ}$. In two cases, the angle of the acetabular labrum was negative resulting from significant head displacement. The study of the acetabulum-head index showed that its value was less than $75-77 \%$ in 9 of 13 patients (Table 2).

\section{Table 2}

Distribution of patients according to acetabulum-head index magnitude

\begin{tabular}{|c|c|c|c|}
\hline \multirow{2}{*}{ Stage } & \multicolumn{3}{|c|}{ Index value } \\
\cline { 2 - 4 } & $<75 \%$ & $<77 \%$ & $>77 \%$ \\
\hline 2 & - & 1 & 1 \\
\hline 3 & 3 & 3 & - \\
\hline $3-4$ & 5 & 3 & - \\
\hline
\end{tabular}

Four patients had aseptic necrosis of the femoral head. One of the symptoms of aseptic necrosis of the femoral head is an increase in the width of the "teardrop", which in one of the patients was $9 \mathrm{~mm}$ on the affected side, and $6.5 \mathrm{~mm}$ on the opposite side (Fig. 4).

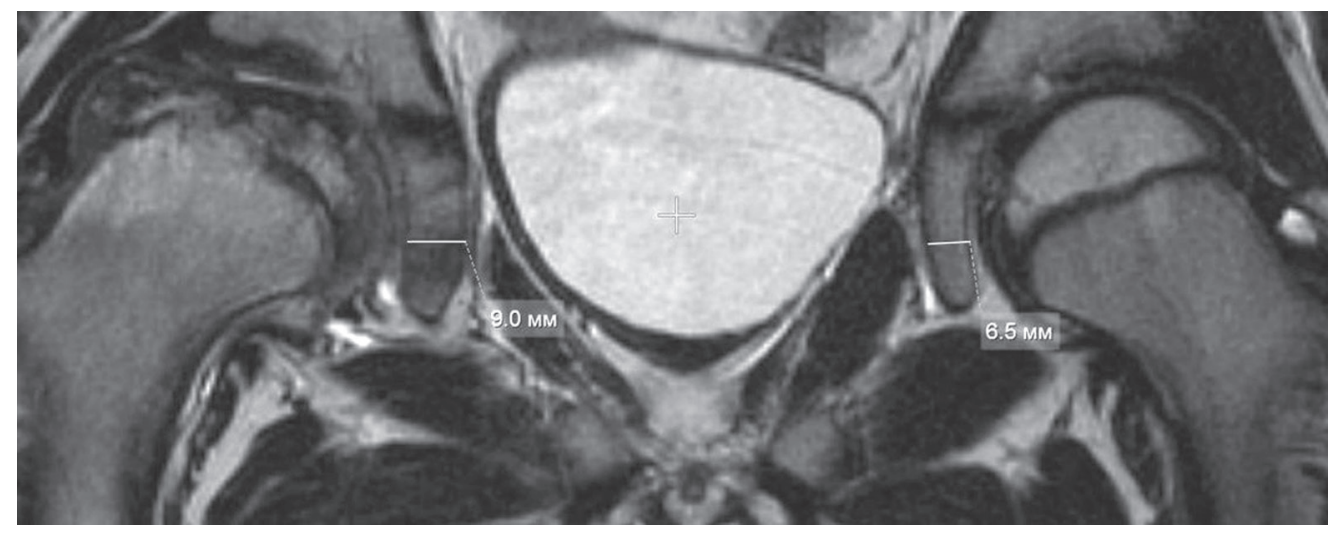

Fig. 4 MRI scan of the hip joints of patient P., 10 years old. Legg-Calvet-Perthes disease, stage III; t2 tse, coronal plane. Increase in the width of the "teardrop figure", horizontalization of the cartilaginous labrum of the acetabulum 
According to MRI, eleven joints in the late stages of the disease showed deformity of the head, a subchondral fragment separated from the head of the femur by a zone of high intensity on T2-WI and a zone of low-intensity on T1-WI, which confirmed the predominance of secondary degenerative changes in the hip joint (coxarthrosis in stage 3-4). Severe changes were observed in patients with bilateral aseptic necrosis, as in patient D., 14 years old, with the third stage of the disease on the right side and second stage on the left. On the right, the femoral head was subtotally destructed, widened, with an uneven contour, fragmented, laterally displaced; the head coverage was up to $50 \%$. The angle of the acetabular labrum was negative $\left(-15^{\circ}\right)$. The articular cartilages of the head and acetabulum were seen fragmented. There was a slight edema of the bone marrow in the structure of the head and neck, an area of necrosis in the upper third of the femur up to $2 \mathrm{~cm}$ in size. The amount of synovial fluid in the joint cavity was increased. On the left, the head was flattened with an impression of the articular surface and its uneven contour. Moderate hypotrophy of the gluteal muscles was observed (Fig. 5).

In the advanced stage of the process, MRI, like all other methods of radiological diagnosis, revealed signs of a dystrophic process in the joint in stage 4 of the disease and deforming arthrosis in stage 3 . Three patients had fungi-shaped femoral head deformity which had the structure of a "baobab crown"; there was shortening of the femoral neck and flattening of the acetabulum. The articular cartilage of the head and acetabulum were unevenly thinned. Head coverage was up to $70 \%$. The articular capsule was thickened, stretched, and formed twists in the anterior and lower parts of the joint. The synovium was diffusely thickened. The amount of synovial fluid in the joint cavity was increased, and it is clearly visualized in Figure 6 c.
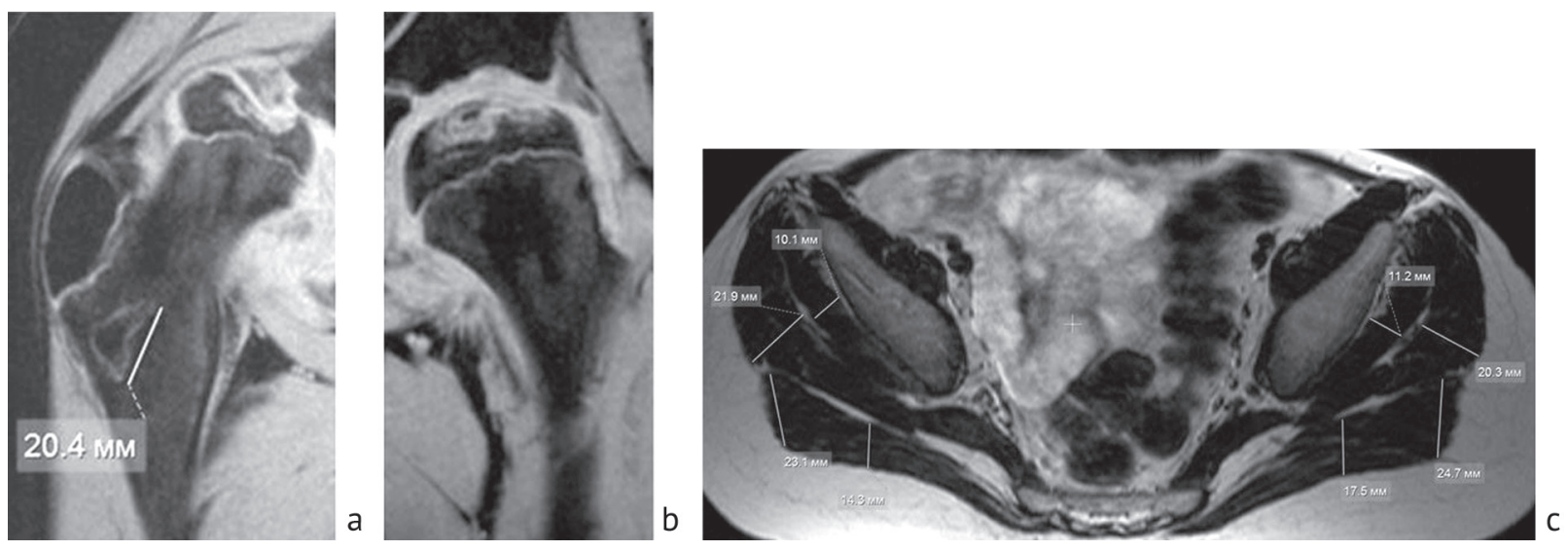

Fig. 5 MRI of the hip joints in patient D., 14 years old. Aseptic necrosis of the femoral head, stage 3 on the right $(a-\mathrm{t} 1 \mathrm{fl} 2 \mathrm{~d}$ fs cor, $b-\mathrm{t} 2$ tse cor), stage 2 on the left ( $c-\mathrm{t} 2$ tse tra). Subluxation of the head on the right. Synovitis. Areas of the pathological signal in the structure of the femurs (foci of necrosis). Gluteal muscle hypotrophy $(c)$
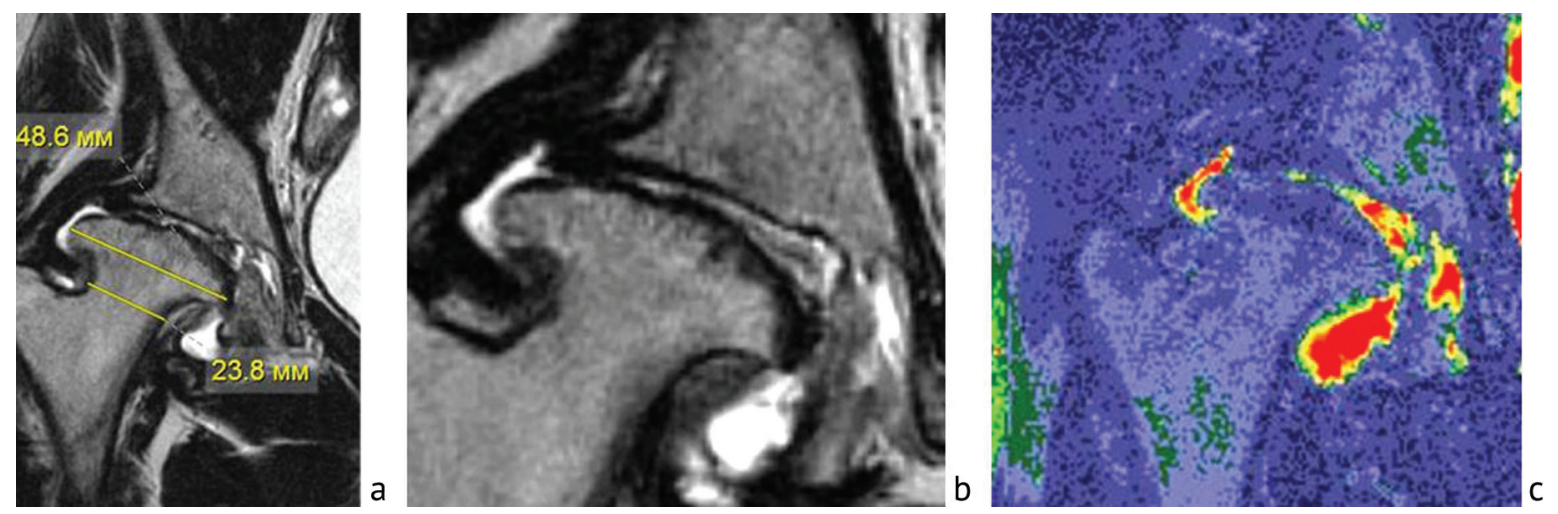

Fig. 6 MRI tomograms of the hip joints in patient B., 17 years old. Frontal plane ( $a, b-\mathrm{t} 2$ tse cor). Color mapping (c). Aseptic necrosis of the femoral head, stage 4 on the right, DOA in stage 3

\section{DISCUSSION}

Special attention has been constantly paid to the study of epidemiology, etiology, diagnosis, treatment of patients with the femoral head AN and Legg-CalvePerthes disease, and a large number of studies have been conducted $[1,5,6,16]$. Many of them are devoted to the problems of early diagnosis of this pathology and the possibilities of modern research methods $[10,15,19]$. MRI has enabled to significantly change the situation with an early detection of the femoral head AN and Legg-Calve-Perthes disease. It opened the possibility 
of monitoring changes in the structure of the head, studying in detail the bone and soft tissue formations of the hip joint, and visualizing the presence of effusion in the joint $[10,11,15,28,29]$. A number of works describe protocols for examining the hip joint with manifestations of inflammation signs in the femoral head, determining the zone and size of necrotic areas, integrity of the joint surface and subchondral fractures. The MRI semiotics of early stages of the disease has been studied [10, 17, 19, 29, 30]. However, patients with pronounced changes in stages 3-4 of the process in the hip joint are frequently admitted to orthopedic clinics. Thus, the task of radiological research methods is no longer to identify initial changes in the femoral head, but to determine the severity of anatomical and topographic disorders in the joint to define the tactics of treatment. This situation took place in our series of cases as long as 12 of 15 patients had stages 3 to 4 of the disease with pronounced changes in all components of the hip joint.

Many authors believe that it is sufficient to use classical radiography in such cases. In our opinion, the need to perform MRI is dictated by many reasons: to reveal the coverage of the head in children, the presence and severity of synovitis, the state of the capsule, visualize the area of edema, assess the state of the articular cartilage and bone marrow changes. The study of radiological changes in patients with Perthes disease usually focuses on the state of the femoral head, while the acetabulum is not always the object of study. There are works that describe labral horizontalization [10]. A more detailed study of the acetabulum with radiography was presented in the work of S. Huhnstock et al., 2017, where the authors expressed the opinion that expansion and hypertrophy of the acetabulum could be caused by hyperemia and higher metabolic activity. The second reason is the change in the size of the femoral head, which prevents the natural inclination of the acetabulum and leads to the horizontalization of the lateral edge [14]. The second reason, from our point of view, is the most probable. An MRI study of the acetabulum by Y. Shirai et al. showed a significant decrease in the angle of the acetabular labrum, which correlated with lateral subluxation and extrusion [10]. It coincides with our data, since complete horizontalization of the labrum was observed in five patients with stages 3-4 of the disease with pronounced lateralization of the head. The angle of the acetabular labrum had a negative value in two patients. In those cases, the head was not only lateralized but also displaced proximally (extrusion). MRI enabled to obtain additional information on the state of the acetabulum, to study it in three planes, to determine the condition and thickness of the articular cartilage, the location of the acetabular labrum, presence and location of foci of edema and destruction in the femoral head.

\section{CONCLUSION}

The complex of pathological changes in the hip joint in Legg-Calve-Perthes disease and AN of the femoral head, especially in children, is most fully detected with MRI. It is able to assess the condition of the femoral head, acetabulum, all soft tissue and cartilaginous formations of the joint, the severity of

synovitis, supplementing the radiographic data at stage 3 to 4 of the disease with signs of deforming arthrosis, when its use is not dictated by algorithms. One of the most important indicators most accurately determined in MRI scans is the lateralization of the acetabular labrum, as well as the acetabulum-head index.

The article was written within the framework of the research topic "Optimization of treatment of children and young patients with necrosis of the femoral head of various etiology and its consequences" of the state assignment for the implementation of scientific research and development of the Federal State Budgetary Institution Ilizarov National Medical Research Centre of the Ministry of Health of Russia.

\section{REFERENCES}

1. Krutikova N.Iu., Vinogradova A.G. Bolezn Legga-Kalve-Pertesa [Legg-Calvé-Perthes disease]. Voprosy Sovremennoi Pediatrii, 2015, vol. 14, no. 5, pp. 548-552. DOI: 10.15690/VSP.V14I5.1437. (in Russian)

2. Pavone V., Chisari E., Vescio A., Lizzio C., Sessa G., Testa G. Aetiology of Legg-Calvé-Perthes disease: A systematic review. World J. Orthop., 2019, vol. 10, no. 3, pp. 145-165. DOI: 10.5312/wjo.v10.i3.145.

3. Loder R.T., Skopelja E.N. The epidemiology and demographics of Legg-Calvé-Perthes' disease. ISRN Orthop., 2011, vol. 2011, pp. 504393. DOI: 10.5402/2011/504393.

4. Mullan C.J., Thompson L.J., Cosgrove A.P. The Declining Incidence of Legg-Calve-Perthes' Disease in Northern Ireland: An Epidemiological Study. J. Pediatr. Orthop., 2017, vol. 37, no. 3, pp. e178-e182. DOI: 10.1097/BPO.0000000000000819.

5. Ibrahim T., Little D.G. The Pathogenesis and Treatment of Legg-Calvé-Perthes Disease. JB JS Rev., 2016, vol. 4, no. 7, pp. 01874474201607000-00003. DOI: 10.2106/JBJS.RVW.15.00063.

6. Kozhevnikov O.V., Lysikov V.A., Ivanov A.V. Bolezn Legga-Kalve-Pertesa: etiologiia, patogenez, diagnostika i lechenie [LeggCalvé-Perthes disease: Etiology, pathogenesis, diagnosis and treatment]. Vestnik Travmatologii i Ortopedii im. N.N. Priorova, 2017, no. 1, pp. 77-87. (in Russian)

7. Mustafin R.N., Khusnutdinova E.K. Avaskuliarnyi nekroz golovki bedrennoi kosti [Avascular necrosis of the femoral head]. Tikhookeanskii Meditsinskii Zhurnal, 2017, no. 1 (67), pp. 27-35. (in Russian)

8. Lespasio M.J., Sodhi N., Mont M.A. Osteonecrosis of the Hip: A Primer. Perm J., 2019, vol. 23, pp. 18-100. DOI: 10.7812/TPP/18-100.

9. Gao F., Han J., He Z., Li Z. Radiological analysis of cystic lesion in osteonecrosis of the femoral head. Int. Orthop., 2018, vol. 42, no. 7, pp. 1615-1621. DOI: 10.1007/s00264-018-3958-z. 
10.Shirai Y., Wakabayashi K., Wada I., Tsuboi Y., Ha M., Otsuka T. MRI appearance in the early stage of Legg-Calvé-Perthes disease to predict lateral pillar classification: A retrospective analysis of the labral horizontalization. J. Orthop. Sci., 2018, vol. 23, no. 1, pp. 161-167. DOI: 10.1016/j.jos.2017.11.009.

11.Jandl N.M., Schmidt T., Schulz M., Rüther W., Stuecker M.H.F. MRI and sonography in Legg-Calvé-Perthes disease: clinical relevance of containment and influence on treatment. J. Child. Orthop., 2018, vol. 12, no. 5, pp. 472-479. DOI: 10.1302/18632548.12.180033.

12.Takashima K., Sakai T., Hamada H., Takao M., Sugano N. Which Classification System is Most Useful for Classifying Osteonecrosis of the Femoral Head? Clin. Orthop. Relat. Res., 2018, vol. 476, no. 6, pp. 1240-1249. DOI: 10.1007/s11999.0000000000000245.

13.ARCO (Association Research Circulation Osseous): Committee on Terminology and Classification. ARCO News, 1992, vol. 4, pp. 41-46.

14.Huhnstock S., Svenningsen S., Merckoll E., Catterall A., Terjesen T., Wiig O. Radiographic classifications in Perthes disease. Acta Orthop., 2017, vol. 88, no. 5, pp. 522-529. DOI: 10.1080/17453674.2017.1340040.

15.Westhoff B., Lederer C., Krauspe R. Morbus Perthes - Neuigkeiten in der Diagnostik und Behandlung [Perthes disease - news in diagnostics and treatment]. Orthopade, 2019, vol. 48, no. 6, pp. 515-522. DOI: 10.1007/s00132-019-03737-2. (in German).

16.Laine J.C., Martin B.D., Novotny S.A., Kelly D.M. Role of advanced imaging in the diagnosis and management of active LeggCalvé-Perthes disease. J. Am. Acad. Orthop. Surg., 2018, vol. 26, no. 15, pp. 526-536. DOI: 10.5435/JAAOS-D-16-00856.

17.Bohndorf K., Roth A. Bildgebung und Klassifikation der aseptischen Hüftkopfnekrose [Imaging and classification of avascular femoral head necrosis]. Orthopade, 2018, vol. 47, no. 9, pp. 729-734. DOI: 10.1007/s00132-018-3615-7. (in German).

18.Trăistaru M.R., Kamal D., Kamal K.C., Rogoveanu O.C., Popescu M., Bondari S., Alexandru D.O., Ionovici N., Grecu D.C. Imaging and histopathological aspects in aseptic osteonecrosis of the femoral head. Rom. J. Morphol. Embryol., 2015, vol. 56, no. 4, pp. 1447-1453.

19.Bunov V.S., Teplenkii M.P., Oleinikov E.V. Osobennosti gemodinamiki v sheike bedrennoi kosti u detei s asepticheskim nekrozom golovki bedra [Characteristic features of hemodynamics in femoral neck of children with femoral head aseptic necrosis]. Genij Ortopedii, 2016, no. 4, pp. 27-35. (in Russian)

20.Martusevich N.A., Gudkevich E.V., Murzich A.E. Rol sosudistykh i metabolicheskikh faktorov v patogeneze netravmaticheskogo asepticheskogo nekroza kostnoi tkani [Role of vascular and metabolic factors in the pathogenesis of non-traumatic aseptic bone tissue necrosis]. Neotlozhnaia Kardiologiia i Kardiovaskuliarnye Riski, 2018, vol. 2, no. 2, pp. 427-431. (in Russian)

21.Borodin S.V., Volkov E.E., Gordeev M.V., Goloshchapov A.P. Faktornyi analiz biokhimicheskikh i klinicheskikh pokazatelei asepticheskogo nekroza golovki bedrennoi kosti [Factor analysis of biochemical and clinical indicators of aseptic necrosis of the femoral head]. Genij Ortopedii, 2018, vol. 24, no. 4, pp. 487-491. (in Russian)

22.Zhang Y., Tian K., Ma X., Zhang L., Sun R., Wang H., Liu Y., Zhou G. Analysis of damage in relation to different classifications of pre-collapse osteonecrosis of the femoral head. J. Int. Med. Res., 2018, vol. 46, no. 2, pp. 693-698. DOI:10.1177/0300060517719625.

23.Zhang Q.Y., Li Z.R., Gao F.Q., Sun W. Pericollapse Stage of Osteonecrosis of the Femoral Head: A Last Chance for Joint Preservation. Chin. Med. J., 2018, vol. 131, no. 21, pp. 2589-2598. DOI: 10.4103/0366-6999.244111.

24.Briukhanov A.V. Magnitno-rezonansnaia tomografiia v diagnostike asepticheskogo osteonekroza golovki bedrennoi kosti (lektsiia) [Magnetic resonance tomography in diagnosing aseptic osteonecrosis of the femoral head (lecture)]. Radiologiia-Praktika, 2014, no. 1, pp. 38-47. (in Russian)

25.Grecula M.J. CORR Insights ${ }^{\circledR}$ : Which Classification System Is Most Useful for Classifying Osteonecrosis of the Femoral Head? Clin. Orthop. Relat. Res., 2018, vol. 476, no. 6, pp. 1250-1252. DOI: 10.1097/01.blo.0000533640.75452.45.

26.Steinberg M.E., Hayken G.D., Steinberg D.R. A quantitative system for staging avascular necrosis. J. Bone Joint Surg. Br., 1995, vol. 77 , no. 1, pp. 34-41.

27.Fletcher R., Fletcher S., Vagner E. Klinicheskaia epidemiologiia. Osnovy dokazatelnoi meditsiny [Clinical Epidemiology. Basics of Evidence-based Medicine]. Bashchinskii S.E., Varshavskii S.Iu., eds. M., MediaSfera, 1998, 352 p. (in Russian)

28.Johnson C.P., Wang L., Tóth F., Aruwajoye O., Carlson C.S., Kim H.K.W., Ellermann J.M. Quantitative MRI Helps to Detect Hip Ischemia: Preclinical Model of Legg-Calvé-Perthes Disease. Radiology, 2018, vol. 289, no. 2, pp. 386-395. DOI: 10.1148/ radiol.2018180497.

29.Hatanaka H., Motomura G., Ikemura S., Kubo Y., Utsunomiya T., Baba S., Kawano K., Nakashima Y. Differences in magnetic resonance findings between symptomatic and asymptomatic pre-collapse osteonecrosis of the femoral head. Eur. J. Radiol., 2019, vol. 112. pp. 1-6. DOI: 10.1016/j.ejrad.2019.01.002.

30.Wu W., He W., Wei Q.-S., Chen Z.-Q., Gao D.-W., Chen P., Zhang Q.-W., Fang B., Chen L.-L., Li B.-L. Prognostic analysis of different morphology of the necrotic-viable interface in osteonecrosis of the femoral head. Int. Orthop., 2018, vol. 42, no. 1, pp. 133139. DOI: $10.1007 / \mathrm{s} 00264-017-3679-8$.

Received: 25.03.2020

\section{Information about the authors:}

1. Galina V. Diachkova, M.D., Ph.D., Professor, Ilizarov National Medical Research Centre for Traumatology and Orthopedics, Kurgan, Russian Federation, Email: dgv_2003@list.ru

2. Mikhail P. Teplenky, M.D., Ph.D., Ilizarov National Medical Research Centre for Traumatology and Orthopedics, Kurgan, Russian Federation

3. Konstantin A. Diachkov, M.D., Ph.D.,

Ilizarov National Medical Research Centre for Traumatology and Orthopedics, Kurgan, Russian Federation,

Email: dka_doc@mail.ru

4. Tat'iana A. Larionova, M.D., Ph.D.,

Ilizarov National Medical Research Centre for Traumatology and Orthopedics, Kurgan, Russian Federation,

Email: lar_rad@mail.ru 